\title{
Models for Predicting Dry Matter Intake of Holsteins During the Prefresh Transition Period
}

\author{
A. Hayirli, ${ }^{\star 1}$ R. R. Grummer,† E. V. Nordheim, $\neq$ and P. M. Crump§ \\ *Department of Animal Nutrition and Nutritional Diseases \\ Ataturk University, Erzurum, 25700 Turkey \\ †Department of Dairy Science, \\ $\ddagger$ Department of Statistics, and \\ $\S$ Computing and Biometry \\ University of Wisconsin, Madison 53706
}

\section{ABSTRACT}

The objectives of this study were to develop and validate a model for predicting dry matter intake (DMI) of Holsteins during the prefresh transition period. The original database (ODB) for model development was established by compiling parity, body condition score (BCS), and DMI data during the final $3 \mathrm{wk}$ of gestation from 366 Holsteins fed 24 different diets that were used in eight experiments conducted at three universities. For model validation, a validation database (VDB) was established by compiling data from 333 prefresh transition Holsteins fed 25 different diets that were used in eight experiments conducted at five universities. Dry matter intake during the prefresh transition period was fitted to an exponential function: $\operatorname{DMI}(t)=\mathrm{a}+\mathrm{pe}^{(\mathrm{kt})}$, where $\operatorname{DMI}(t)=\mathrm{DMI}$ as a percentage of body weight (BW) at time t, a = asymptotic intercept at time $-\infty, \mathrm{p}$ $=$ change in intake $(\mathrm{kg})$ from the asymptotic intercept until parturition, $\mathrm{k}=$ rate constant influencing the shape of the curve, and $t=$ day relative to parturition expressed as days pregnant -280 . The model developed from the ODB predicted DMI of heifers in the VDB with satisfactory accuracy and precision. However, this was not true for cows, probably due to differences in BCS of cows and diets fed to cows from the two data sets. When a subset of cows was selected from each data set that had similar BCS (> 4.0) and were fed similar diets, accuracy and precision of the model predicting DMI was improved. Finally, both databases were combined to develop final models for predicting DMI of heifers and cows. Proposed models for predicting mean daily DMI of heifers and cows during the prefresh transition period were $\operatorname{DMI}(t)=1.713-0.688 \mathrm{e}^{(0.344 t)}\left(\mathrm{R}^{2}=0.96\right)$ and $\operatorname{DMI}(\mathrm{t})=1.979-0.756 \mathrm{e}^{(0.154 \mathrm{t})}\left(\mathrm{R}^{2}=0.97\right)$, respectively. Adjustment factors for animal and dietary factors were

Received May 10, 2002.

Accepted October 20, 2002.

Corresponding author: Ric R. Grummer; e-mail: rgrummer@ wisc.edu. generated to demonstrate the plausibility of adaptive fitting of the prediction. The regression coefficients of prediction models ( $\mathrm{a}, \mathrm{p}$, and $\mathrm{k}$ ) were affected by BCS and dietary organic macronutrient concentrations.

(Key words: dry matter intake, model, prefresh transition period)

\begin{abstract}
Abbreviation key: $\mathbf{a}=$ asymptotic intercept at time $-\infty, \mathbf{A D M I}=$ actual dry matter intake, $\mathbf{B}=$ bias (predicted DMI - actual DMI), OC = obese cows (BCS > 4.0), ODB = original database, $\mathbf{p}=$ change in intake (kg) from the asymptotic intercept until parturition, PDMI = predicted dry matter intake, RPE $=$ relative prediction error, $\mathbf{t}=$ day relative to parturition expressed as days pregnant $-280, \mathbf{V D B}=$ validation database.
\end{abstract}

\section{INTRODUCTION}

The prefresh transition period covers the final $3 \mathrm{wk}$ of gestation when dynamic physiological changes occur (Van Saun, 1991; Bell, 1995; Nocek, 1995). The previous NRC (1989) recommended uniform dietary nutrient concentrations throughout the dry period. However, DMI decreases by 35\% as cows approach parturition (Marquardt et al., 1977). Therefore, increasing nutrient density of the diet during the prefresh transition period may be necessary to meet nutrient demands by maternal and fetal tissues and to facilitate transition from gestation to lactation (Van Saun, 1991; Grummer, 1995).

Diets are typically formulated based on nutrient density. Because nutrient intake is a function of DMI, predicting DMI precisely and accurately is important to prepare balanced rations when on farm estimates of feed intake are not available. Several models for predicting DMI of lactating cows have been developed (Kertz et al., 1991; Roseler et al., 1997). To our knowledge, there is no available model for predicting DMI during the prefresh transition period. Numerous factors affect feed intake in ruminants (NRC, 1987). Using 
HAYIRLI ET AL.

Table 1. Characteristics of animals in the original and validation databases.

\begin{tabular}{|c|c|c|c|c|c|}
\hline \multirow[b]{3}{*}{ Database $^{2}$} & \multicolumn{5}{|c|}{ Measurement ${ }^{1}$} \\
\hline & \multirow[b]{2}{*}{$\mathrm{n}$} & \multicolumn{2}{|c|}{ Body weight (kg) } & \multicolumn{2}{|c|}{ Body condition score } \\
\hline & & $\mathrm{WM} \pm \mathrm{SD}$ & Range & $\mathrm{WM} \pm \mathrm{SD}$ & Range \\
\hline \multicolumn{6}{|l|}{ ODB } \\
\hline \multicolumn{6}{|l|}{ Parity } \\
\hline Heifer & 155 & $605 \pm 53$ & $471-811$ & $3.6 \pm 0.4$ & $2.7-4.9$ \\
\hline Cow & 211 & $732 \pm 77$ & $514-960$ & $3.6 \pm 0.5$ & $2.0-4.9$ \\
\hline \multicolumn{6}{|c|}{ Body Condition } \\
\hline Thin & 49 & $639 \pm 91$ & $480-859$ & $2.9 \pm 0.2$ & $2.0-3.0$ \\
\hline Medium & 256 & $667 \pm 84$ & $471-960$ & $3.6 \pm 0.3$ & $3.1-4.0$ \\
\hline Obese & 53 & $753 \pm 86$ & $546-908$ & $4.4 \pm 0.2$ & $4.1-5.0$ \\
\hline \multicolumn{6}{|l|}{ VDB } \\
\hline \multicolumn{6}{|l|}{ Parity } \\
\hline Heifer & 17 & $607 \pm 50$ & $540-685$ & $3.7 \pm 0.1$ & $3.4-3.9$ \\
\hline Cow & 316 & $734 \pm 76$ & $526-945$ & $3.5 \pm 0.4$ & $2.2-5.0$ \\
\hline \multicolumn{6}{|c|}{ Body Condition } \\
\hline Thin & 26 & $678 \pm 71$ & $526-819$ & $2.8 \pm 0.2$ & $2.2-3.0$ \\
\hline Medium & 260 & $725 \pm 73$ & $540-944$ & $3.6 \pm 0.2$ & $3.1-4.0$ \\
\hline Obese & 47 & $835 \pm 56$ & $721-937$ & $4.3 \pm 0.2$ & $4.1-5.0$ \\
\hline
\end{tabular}

\footnotetext{
${ }^{1}$ Measurements were obtained on d $21 \pm 0.8$ (mean $\pm \mathrm{SD}$ ) prepartum. WM $\pm \mathrm{SD}=$ weighted mean \pm standard deviation.

${ }^{2}$ Database: $\mathrm{ODB}=$ original database; $\mathrm{VDB}=$ validation database; Thin $=$ if $1 \leq \mathrm{BCS} \leq 3$; Medium $=$ if $3<$ $\mathrm{BCS} \leq 4 ;$ Obese $=$ if $4<\mathrm{BCS} \leq 5$.
}

a large database, Hayirli et al. (2002) previously evaluated some animal and dietary factors affecting DMI during the final $3 \mathrm{wk}$ of gestation as a prerequisite of modeling DMI. In the present study, our objectives were to develop and validate a model for predicting DMI of prefresh transition Holsteins that could be incorporated into diet formulation programs and the model for the 7th revision of Nutrient Requirements of Dairy Cattle (NRC, 2001).

\section{MATERIALS AND METHODS}

\section{Data Collection and Development of Databases}

Parity, BW, BCS, and DMI data during the final 3 wk of gestation of 366 Holsteins fed 24 different diets were compiled from eight experiments conducted at Iowa State University (Hayirli, 1997), Michigan State University (VandeHaar et al., 1999; Moore et al., 2000), and the University of Wisconsin (Skaar et al., 1989; Bertics et al., 1992; Grummer et al., 1995; VazquezAnon et al., 1997; Minor et al., 1998) to generate the original database (ODB) for model development. Data on the same variables from 333 prefresh transition Holsteins fed 25 different diets involving eight experiments conducted at Cornell University (Van Saun et al., 1993), Oregon State University (Allen et al., 1995; Duncan, 1998), Pennsylvania State University (Dann et al., 1999; Soder and Holden, 1999), Purdue University (Greenfield et al., 2000), and the University of Illinois (Grum et al., 1996; Overton et al., 1998) were compiled to generate the database for model validation (VDB).
Order in which the data were received was the only factor determining which database cows were placed in.

Data from animals that were not fed ad libitum, or that had twins were excluded from both databases. Daily DMI during the prefresh transition period and BW and BCS (Edmonson et al., 1989) on d $21 \pm 0.8$ (mean \pm SD) prepartum were measured for all animals. Detailed descriptions of animal and dietary factors in all experiments were previously published (Hayirli et al., 2002). For this study, animals approaching the first lactation and the second or greater lactation were categorized as heifers and cows, respectively (Table 1). Animals were also categorized as thin, medium, and obese if their BCS ranged from 1 to $3,3.01$ to 4 , and 4.01 to 5 , respectively (Table 1). Dietary factors were continuous variables and included concentrations of $\mathrm{NE}_{\mathrm{L}}, \mathrm{CP}, \mathrm{RUP}$, RDP, NDF, nonfiber carbohydrate (NFC), ADF, ether extract (EE), and ash (Table 2).

\section{Statistics, Calculations, and Protocol for Model Validation}

Dry matter intake was expressed as a percentage of BW for model development so that variability due to body size was minimized. Descriptive statistics of animal and dietary factors in the ODB and VDB were determined using the Means, Freq, and Univariate Procedures (SAS, 1998). In both databases, proportions of variation in DMI contributed by animal and dietary factors were calculated from their type III sums of squares in a linear multivariable mixed model using 
Table 2. Characteristics of diets in the original and validation databases. ${ }^{1}$

\begin{tabular}{lcccrr}
\hline & \multicolumn{5}{c}{ Descriptive statistics } \\
\cline { 2 - 5 } Database $^{2}$ & Range & WM \pm SD $^{3}$ & Median & Mode & Skewness \\
\hline ODB & & & & \\
NE, Mcal/kg & $1.30-1.66$ & $1.48 \pm 0.12$ & 1.47 & 1.35 & 0.09 \\
CP, \% & $12.2-20.3$ & $15.7 \pm 2.1$ & 15.8 & 15.7 & 0.43 \\
RUP, \% & $3.4-6.3$ & $5.3 \pm 0.8$ & 5.4 & 5.3 & -0.98 \\
RDP, \% & $8.0-14.1$ & $10.4 \pm 1.8$ & 10.3 & 10.4 & 0.92 \\
NDF, \% & $28.0-51.5$ & $41.1 \pm 8.6$ & 43.6 & 34.6 & -0.27 \\
ADF, \% & $16.6-41.1$ & $19.0 \pm 6.6$ & 29.6 & 27.0 & -0.02 \\
NFC, \% & $22.5-46.2$ & $32.4 \pm 8.2$ & 31.5 & 37.8 & 0.29 \\
EE, \% & $1.8-4.9$ & $3.1 \pm 0.9$ & 3.0 & 4.9 & 0.67 \\
Ash, \% & $6.4-11.7$ & $7.7 \pm 1.2$ & 7.2 & 7.0 & 1.85 \\
VDB & & & & & \\
NE, Mcal/kg & $1.27-1.64$ & $1.50 \pm 0.09$ & 1.51 & 1.50 & -0.97 \\
CP, \% & $11.8-16.40$ & $13.7 \pm 1.1$ & 13.5 & 14.1 & 1.3 \\
RUP, \% & $3.2-6.6$ & $4.6 \pm 0.7$ & 4.7 & 4.9 & 0.6 \\
RDP, \% & $7.4-12.1$ & $9.1 \pm 0.9$ & 9.0 & 9.2 & 1.51 \\
NDF, \% & $35.6-62.2$ & $46.0 \pm 7.4$ & 44.5 & 44.5 & 0.55 \\
ADF, \% & $24.4-38.5$ & $28.6 \pm 3.8$ & 27.7 & 25.2 & 0.95 \\
NFC, \% & $10.5-44.0$ & $31.0 \pm 8.3$ & 33.2 & 33.9 & -0.46 \\
EE, \% & $2.2-6.9$ & $3.6 \pm 1.3$ & 3.1 & 3.7 & 1.67 \\
Ash, \% & $3.3-7.8$ & $5.7 \pm 1.5$ & 6.1 & 33.3 & -0.32 \\
\hline
\end{tabular}

\footnotetext{
${ }^{1}$ Nutrients were on a DM basis.

${ }^{2}$ Database: $\mathrm{ODB}=$ original database VDB = validation database NFC = nonfiber carbohydrate $; \mathrm{EE}=$ ether extract.

${ }^{3} \mathrm{WM} \pm \mathrm{SD}=$ weighted mean \pm standard deviation.
}

the MIXED Procedure (SAS, 1998). The models for predicting DMI were generated by the Gauss-Newton method using the NLIN procedure (SAS, 1998) before and after reducing DMI data to daily means. The equation describing DMI during the prefresh transition period was adapted from a differential equation of Newton's law of cooling as described by Berkey (1994), which was as follows:

$$
\operatorname{DMI}(\mathbf{t})=\mathbf{a}+\mathbf{p e}^{(\mathrm{kt})}
$$

where $\mathrm{DMI}(\mathrm{t})=\mathrm{DMI}$ as a percentage of $\mathrm{BW}$ at time $\mathrm{t}$, $\mathrm{a}=$ asymptotic intercept at time $-\infty, \mathrm{k}=$ rate constant influencing shape of the curve, $p=$ the change in intake (kg) from the asymptotic intercept until parturition, and $t=$ day relative to parturition expressed as days pregnant - 280. DMI as a percentage of BW at any given time was always expressed as a percentage of BW recorded at $d 21 \pm 0.8$. This was necessary because for most cows, only one BW measurement was obtained during the prepartum period.

Validation of models was conducted in three stages (Neter et al., 1990; Draper and Smith, 1996). First, significance of differences between regression coefficients of prediction models (i.e., a, p, and k) from ODB and VDB was determined using the $\mathrm{Z}$ distribution (Draper and Smith, 1996). Second, models developed from the ODB for heifers and cows were used to predict DMI for the corresponding category of animals in the
VDB. Because "t" is the only independent variable in our prediction models, predicted DMI (PDMI) is the same for all animals within the same parity category. Therefore, for the validation process, PDMI and actual DMI (ADMI) values were converted from a percentage of BW to kg per day. Depending on the evaluation described below, ADMI or PDMI (kg per day) during the final 3 wk of gestation were averaged by animal or by day. To determine accuracy and precision of the prediction models, intercepts, slopes, and $\mathrm{R}^{2}$ of relationships between average ADMI and PDMI for each animal during the final 3 wk of gestation, bias (B; predicted actual) and average ADMI for each animal during the final 3 wk of gestation, and B and day relative to parturition (t) for each day were determined using the Reg Procedure (SAS, 1998). Third, a t-test was used to determine if $B$ values were different from zero or if slopes were different from 0 or 1.

Correlation between ADMI and PDMI ( $\mathrm{r}_{\mathrm{ADMI}}$,PDMI $)$ determines accuracy of the prediction and indicates closeness of PDMI and ADMI. Relative prediction error (RPE) determines precision of the prediction and indicates reproducibility of the prediction. Accuracy and precision of the prediction models were determined as described by Eastridge et al. (1998) using the following equations:

$$
\begin{gathered}
\mathrm{MSPE}=\Sigma\left[(\mathrm{ADMI}-\mathrm{PDMI})^{2}+\mathrm{S}_{\mathrm{PDMI}}^{2}\left(1-\mathrm{b}_{\mathrm{ADMI}, \mathrm{PDMI}}\right)\right. \\
\left.+\mathrm{S}_{\mathrm{ADMI}}^{2}\left(1-\mathrm{R}^{2}\right)\right]
\end{gathered}
$$




$$
\begin{aligned}
\mathrm{MPE} & =\text { square root of MSPE } \\
\mathrm{RPE} & =100(\mathrm{MPE} / \mathrm{aADMI})
\end{aligned}
$$

where MSPE $=$ mean square prediction error, $\mathrm{S}^{2}$ PDMI $=$ variance of PDMI, $b_{\mathrm{ADMI}, \mathrm{PDMI}}=$ slope of the regression of ADMI on PDMI, $\mathrm{S}^{2}{ }_{\mathrm{ADMI}}=$ variance of $\mathrm{ADMI}, \mathrm{R}^{2}=$ model variance explained by $\mathrm{b}_{\mathrm{ADMI}, \mathrm{PDMI}}, \mathrm{MPE}=$ mean prediction error, $\mathrm{RPE}=$ relative prediction error, and aADMI $=$ average ADMI.

Precision and accuracy of the model generated from the ODB for predicting DMI of heifers was greater than the model generated for predicting DMI of cows (see results and discussion). It was speculated that inconsistencies between ODB and VDB in BCS of cows and diets fed to cows partially accounted for the low precision and accuracy. Therefore, a subset of cows with BCS $>4$ (OC) that were fed more similar diets were generated from the ODB and VDB and the validation process was repeated.

Finally, we combined both databases to develop final prediction models. The exponential prediction model is only a function of time. Animal and dietary factors are not parts of regression coefficients of the prediction models. We intended to incorporate these factors into a single model for predicting DMI of all animals, however, this resulted in over-parameterization. Thus, the exponential model for predicting DMI of each animal was selected. The Reg procedure (SAS, 1998) was used to examine the effects of animal and dietary factors on model coefficients of the exponential model for predicting DMI. Estimates for adjustment of each model coefficient for animal and dietary factors are reported to demonstrate the plausibility of adaptive fitting of the prediction models. Any $P$ value $<0.05$ for this or other analysis were declared to be significant.

\section{RESULTS AND DISCUSSION}

\section{Model Validation}

Comparison of model coefficients. Exponential models for predicting DMI of heifers, cows, and OC in the ODB and VDB are summarized in Table 3. These models were developed after DMI values within each data set were reduced to daily means. Coefficients (a, $\mathrm{p}$ and $\mathrm{k}$ ) were not different if models were generated from the complete data set, however, $\mathrm{R}^{2}$ values were much lower $(0.06,0.06$, and 0.20 for heifers, cows and $\mathrm{OC}$ in the ODB and $0.36,0.15$, and 0.24 for heifers, cows and OC in the VDB). Dramatic improvements in the $\mathrm{R}^{2}$ of prediction models developed after reducing data to daily means (Table 3 ) indicate that there is substantial variability in DMI between animals within days.
Models for predicting DMI of heifers and cows in the ODB were $\operatorname{DMI}(\mathrm{t})=1.710-0.611 \mathrm{e}^{(0.332 \mathrm{t})}\left(\mathrm{R}^{2}=0.96\right)$ and $\operatorname{DMI}(\mathrm{t})=1.961-0.742 \mathrm{e}^{(0.268 \mathrm{t})}\left(\mathrm{R}^{2}=0.96\right)$, respectively. In the ODB, the coefficients "a" $(P<0.0001)$ and "p" $(P$ $<0.04$ ) for heifers and cows were different; but the coefficient " $\mathrm{k}$ " was not $(P<0.17)$. Models for predicting DMI of heifers and cows in the VDB were DMI $(\mathrm{t})=$ $1.714-1.486 \mathrm{e}^{(0.485 \mathrm{t})}\left(\mathrm{R}^{2}=0.91\right)$ and $\mathrm{DMI}(\mathrm{t})=2.029-$ $0.841 \mathrm{e}^{(0.112 \mathrm{t})}\left(\mathrm{R}^{2}=0.97\right)$, respectively. In the VDB, all coefficients for heifers and cows were different $(P<$ $0.0001, P<0.001$, and $P<0.0001$ for a, $\mathrm{p}$, and $\mathrm{k}$, respectively; Table 3). These results indicate that DMI of heifers and cows during the final 3 wk of gestation vary within databases.

Models for predicting daily DMI of heifers in the ODB and VDB were $\operatorname{DMI}(\mathrm{t})=1.710-0.611 \mathrm{e}^{(0.332 \mathrm{t})}\left(\mathrm{R}^{2}=0.96\right)$ and $\operatorname{DMI}(\mathrm{t})=1.714-1.486 \mathrm{e}^{(0.485 \mathrm{t})}\left(\mathrm{R}^{2}=0.91\right)$, respectively. The coefficient "p" was different between databases $(P<0.0001)$; but the coefficient "a" $(P<0.88)$ and "k" $(P<0.07)$ were not. Models for predicting daily DMI of cows in the ODB and VDB were $\operatorname{DMI}(\mathrm{t})=1.961-$ $0.742 \mathrm{e}^{(0.268 \mathrm{t})}\left(\mathrm{R}^{2}=0.96\right)$ and $\mathrm{DMI}(\mathrm{t})=2.029-0.841 \mathrm{e}^{(0.112 \mathrm{t})}$ $\left(R^{2}=0.97\right)$, respectively. The coefficient " $k$ " was different between databases $(P<0.0001)$; but the coefficients "a" $(P<0.17)$ and "p" $(P<0.10)$ were not. These results suggest that within each database, DMI during the final 3 wk of gestation varied between heifers and cows.

Models for predicting daily DMI during the final 3 wk of gestation of OC in the ODB and VDB were DMI(t) $=2.03-1.002 \mathrm{e}^{(0.131 \mathrm{t})}\left(\mathrm{R}^{2}=0.97\right)$ and $\mathrm{DMI}(\mathrm{t})=1.960-$ $1.016 \mathrm{e}^{(0.106 \mathrm{t})}\left(\mathrm{R}^{2}=0.96\right)$, respectively. None of the regression coefficients of these prediction models were different $(P<0.38, P<0.83$, and $P<0.34$ for the coefficients "a", "p", and "k", respectively; Table 3). Before reducing DMI data to daily means, $R^{2}$ of models for predicting DMI of OC in ODB (0.20) and VDB (0.24) were greater than $\mathrm{R}^{2}$ of models for predicting DMI of all cows in the ODB (0.09) and VDB (0.15), respectively (Table 3). This reflects greater homogeneity of DMI by cows in the OC subset compared to that of all cows.

Evaluation of functional relationships. Figure 1 illustrates PDMI and daily means for ADMI of heifers $(\mathrm{n}=17)$, cows $(\mathrm{n}=316)$, and OC $(\mathrm{n}=47)$ in the VDB during the prefresh transition period. The model continuously over-predicted ADMI of cows and OC during the final 3 wk of gestation, whereas the model only overpredicted DMI of heifers during the final week of gestation.

The relationships between average ADMI during the final $3 \mathrm{wk}$ of gestation for animals in the VDB and PDMI based on the ODB was ADMI $=0.84 \mathrm{PDMI}+1.40$ $\left(\mathrm{R}^{2}=0.42\right)$ for heifers, $\mathrm{ADMI}=0.44 \mathrm{PDMI}+6.46\left(\mathrm{R}^{2}=\right.$ $0.05)$ for cows, and ADMI $=0.69 \mathrm{PDMI}+3.00\left(\mathrm{R}^{2}=0.41\right)$ for OC, respectively (Figure 2). Ideally, regression of 
Table 3. Models for predicting DMI as a percentage of BW of prefresh transition Holsteins and comparisons of regression coefficients of the models within and between databases.

\begin{tabular}{|c|c|c|c|c|c|c|c|c|c|c|c|}
\hline \multirow[b]{4}{*}{ Coefficients $^{3}$} & \multicolumn{6}{|c|}{ Database $^{1}$} & & & & & \\
\hline & \multicolumn{3}{|c|}{ ODB } & \multicolumn{3}{|c|}{ VDB } & \multirow{2}{*}{\multicolumn{5}{|c|}{ Statistical contrasts ${ }^{2}, P>\mathrm{Z}$}} \\
\hline & Heifer & Cow & $\mathrm{OC}$ & Heifer & Cow & $\mathrm{OC}$ & & & & & \\
\hline & $(155)$ & $(211)$ & $(53)$ & $(17)$ & $(316)$ & $(47)$ & A & B & $\mathrm{C}$ & $\mathrm{D}$ & $\mathrm{E}$ \\
\hline a & 1.710 & 1.961 & 2.031 & 1.714 & 2.029 & 1.960 & 0.0001 & 0.0001 & 0.88 & 0.17 & 0.38 \\
\hline$-p$ & 0.611 & 0.742 & 1.002 & 1.486 & 0.841 & 1.016 & 0.04 & 0.001 & 0.0001 & 0.10 & 0.83 \\
\hline $\mathrm{k}$ & 0.332 & 0.268 & 0.131 & 0.485 & 0.112 & 0.106 & 0.17 & 0.0001 & 0.07 & 0.0001 & 0.34 \\
\hline $\mathrm{R}^{2}$ & 0.96 & 0.96 & 0.97 & 0.91 & 0.97 & 0.96 & $\ldots$ & $\ldots$ & $\ldots$ & $\ldots$ & \\
\hline
\end{tabular}

${ }^{1}$ Database: $\mathrm{ODB}=$ original database; $\mathrm{VDB}=$ validation database; $\mathrm{OC}=$ obese cows $(\mathrm{BCS}>4)$. Numbers in parenthesis indicate the number of animals.

${ }^{2}$ Statistical contrasts: $\mathrm{A}=$ heifer vs. cow in ODB; $\mathrm{B}=$ heifer vs. cow in VDB; $\mathrm{C}=\mathrm{ODB}$ vs. VDB for heifer; $\mathrm{D}=\mathrm{ODB}$ vs. VDB for cow; $\mathrm{E}=\mathrm{ODB}$ vs. VDB for OC. Probability of significance was obtained by pair-wise comparison of regression coefficients using Z-test.

${ }^{3}$ Coefficients of nonlinear equations $\left(\mathrm{DMI}(\mathrm{t})=\mathrm{a}+\mathrm{pe}{ }^{(\mathrm{kt})}\right)$ were obtained after reducing data to daily means, where DMI $(\mathrm{t})=\mathrm{DMI}$ as a percentage of body weight $(\mathrm{BW})$ at time $t, a=$ asymptotic intercept at time $-\infty$, $\mathrm{p}=$ change in intake $(\mathrm{kg})$ from the asymptotic intercept until parturition, $\mathrm{k}=$ rate constant influencing the shape of the curve, and $t=$ day relative to parturition expressed as days pregnant -280 . DMI as a percentage of BW at any given time was always expressed as a percentage of BW recorded at d $21 \pm 0.8 . R^{2}=[1-$ (residual/corrected total)].

ADMI on PDMI would be ADMI = PDMI, with intercept being equal to zero and slope and correlation coefficient being equal to one. The intercept (1.40) and slope (0.84) for heifers were not different from zero $(P<0.59)$ and one $(P<0.53)$, respectively. However, the intercept (6.46) and slope (0.44) for cows were different from zero and one $(P<0.0001$ for both). The intercept (3.00) and slope $(0.69)$ for OC were not different from zero $(P<$ $0.50)$ and one $(P<0.33)$, respectively. Numerically, the intercept was closer to zero and the slope closer to one for OC than for all cows. The $\mathrm{R}^{2}$ of the functional relationship between ADMI and PDMI improved dramati-

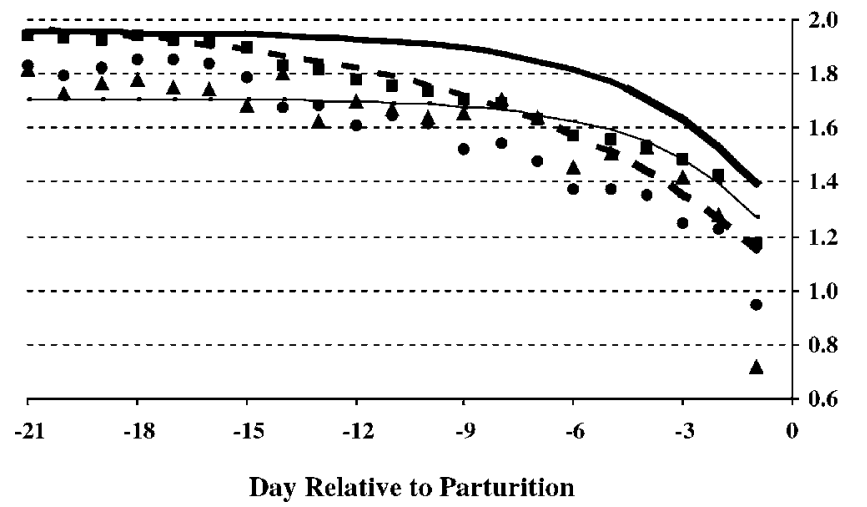

Figure 1. Daily means of actual DMI and predicted DMI of heifers $(-, \mathbf{\Delta})$, cows $(-, \boldsymbol{\square})$, and obese cows $(---, \mathbf{0})$ from the validation database during the final 3 wk of gestation. DMI is expressed as a percentage of $\mathrm{BW}$ recorded at d $21 \pm 0.8$. Average SD of actual daily DMI of heifers $(\mathrm{n}=17)$, cows $(\mathrm{n}=316)$, and obese cows $(\mathrm{n}=57)$ were $0.13,0.39$, and 0.36 and average SE of predicted daily DMI of heifers $(\mathrm{n}=155)$, cows $(\mathrm{n}=211)$, and obese cows $(\mathrm{n}=47)$ were $0.0002,0.001$, and 0.007 , respectively. cally for OC compared to all cows. These results suggest selection of a subset of cows from ODB and VDB that are more homogenous with respect to BCS and diet leads to generation of better prediction equations for DMI during the final 3 wk of gestation.

Bias refers to a systematic as opposed to a random difference between PDMI and ADMI. Because B is related to accuracy of a prediction model, it is sometimes incorrectly used to describe prediction error. We used $\mathrm{B}$ to determine over- or under-prediction, not precision. In the present study, the model over- or under-predicts DMI if $B$ is positive or negative, respectively. The relationships between average $\mathrm{B}$ and $\mathrm{ADMI}$ during the final $3 \mathrm{wk}$ of gestation was $\mathrm{B}=-0.49 \mathrm{ADMI}+5.02\left(\mathrm{R}^{2}=0.76\right)$

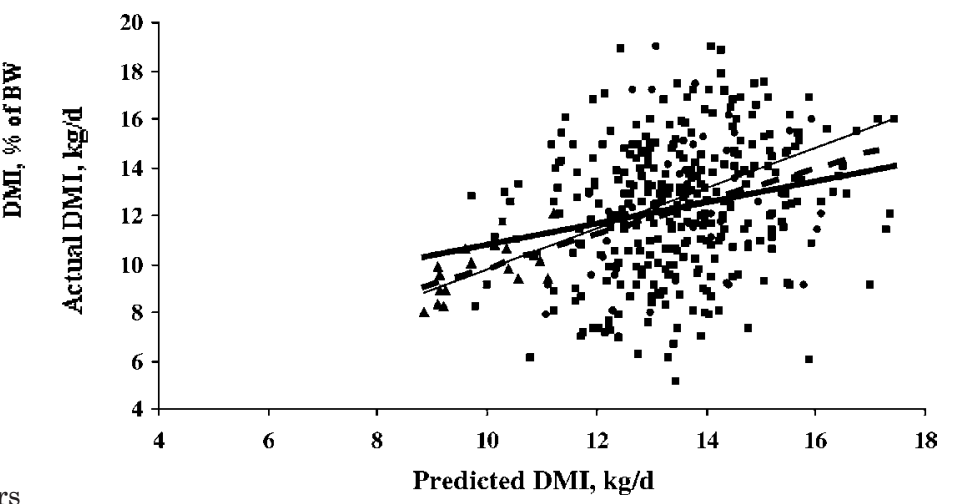

Figure 2. Relationships between average actual and predicted DMI of heifers $\left(-, \mathbf{\Delta}\right.$; ADMI $\left.=0.84 \mathrm{PDMI}+1.40, \mathrm{R}^{2}=0.42\right)$, cows ( $\mathbf{D}$; $\left.\mathrm{ADMI}=0.44 \mathrm{PDMI}+6.46, \mathrm{R}^{2}=0.05\right)$, and obese cows $\left(--, \bullet\right.$ ADMI $\left.=0.69 \mathrm{PDMI}+3.00, \mathrm{R}^{2}=0.41\right)$ from the validation database during the final $3 \mathrm{wk}$ of gestation. ADMI = actual DMI, PDMI = predicted DMI. 


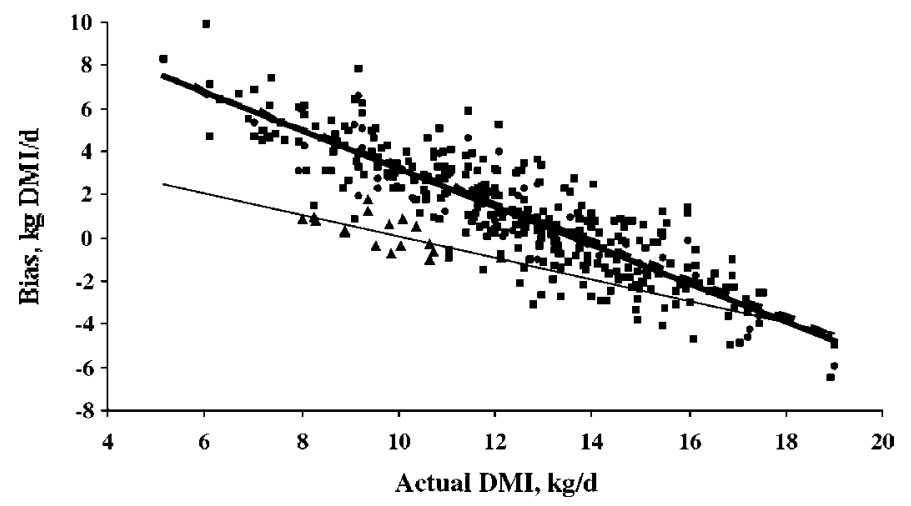

Figure 3. Relationships between average actual DMI and bias for heifers (-, $\left.\mathbf{\Delta} ; \mathrm{B}=-0.89 \mathrm{ADMI}+12.08, \mathrm{R}^{2}=0.76\right)$, cows $(-, \mathbf{\square} ; \mathrm{B}=$ $\left.-0.49 \mathrm{ADMI}+5.02, \mathrm{R}^{2}=0.41\right)$, and obese cows $(---, \mathbf{0} ; \mathrm{B}=-0.87 \mathrm{ADMI}$ $+11.98, R^{2}=0.81$ ) from the validation database during the final 3 wk of gestation. $\mathrm{B}=$ bias, $\mathrm{ADMI}=$ actual DMI.

for heifers, $\mathrm{B}=-0.89 \mathrm{ADMI}+12.08\left(\mathrm{R}^{2}=0.41\right)$ for cows, and $\mathrm{B}=-0.87 \mathrm{ADMI}+11.98\left(\mathrm{R}^{2}=0.81\right)$ for OC, respectively (Figure 3). The DMI model derived from the ODB over-predicted ADMI of heifers in the VDB when they consumed less than $10 \mathrm{~kg}$ per day and under-predicted ADMI of cows and OC in the VDB when they consumed more than $14 \mathrm{~kg}$ per day during the final $3 \mathrm{wk}$ of gestation, respectively (Figure 3). Ideally, regression of $\mathrm{B}$ on $\mathrm{ADMI}$ would be $\mathrm{B}=0$, with intercept and slope being equal to zero. The intercepts for heifers (5.02) and cows (12.08) were different from zero $(P<0.0001)$. The slope for cows $(-0.89)$ was different from zero $(P<0.0001)$, whereas for heifers $(-0.49)$ it was not $(P<0.06)$. The intercept (11.98) and slope (-0.87) for OC were different from zero $(P<0.0001$ for both $)$.

The prediction models generated from the ODB increasingly over-predicted daily means of ADMI for heifers $\left(B=0.09 t+1.17, R^{2}=0.42\right)$ and cows $(B=0.08 t+$ $\left.1.88, \mathrm{R}^{2}=0.71\right)$ in the VDB as they approached parturition. For $\mathrm{OC}\left(\mathrm{B}=0.003 \mathrm{t}+1.20, \mathrm{R}^{2}=0.002\right) \mathrm{ADMI}$ was consistently overpredicted by approximately $1 \mathrm{~kg} /$ $\mathrm{d}$ (Figure 4). Ideally, regression of $\mathrm{B}$ on time would be $\mathrm{B}=0$, with intercept and slope being equal to zero. The intercepts for heifer $(1.17 ; P<0.0008)$ and cows $(1.88$; $P<0.0008)$ and the slopes for heifers $(0.09 ; P<0.002)$ and cows $(0.08 ; P<0.0001)$ were different from zero. The intercept (1.20) for OC was different from zero $(P$ $<0.0001)$ but the slope $(0.003)$ was not $(P<0.83)$.

Evaluation of the strength of predictions. For the final $3 \mathrm{wk}$ of gestation, the difference between average daily PDMI and ADMI of heifers from the VDB was not different from zero (mean bias $=0.22 \mathrm{~kg} \mathrm{DMI} / \mathrm{d}, P$ $<0.28$; Table 4). Precision and accuracy of the model for predicting DMI of heifers were 9.25 and $65.0 \%$, respectively. In contrast, ADMI of cows in the VDB was

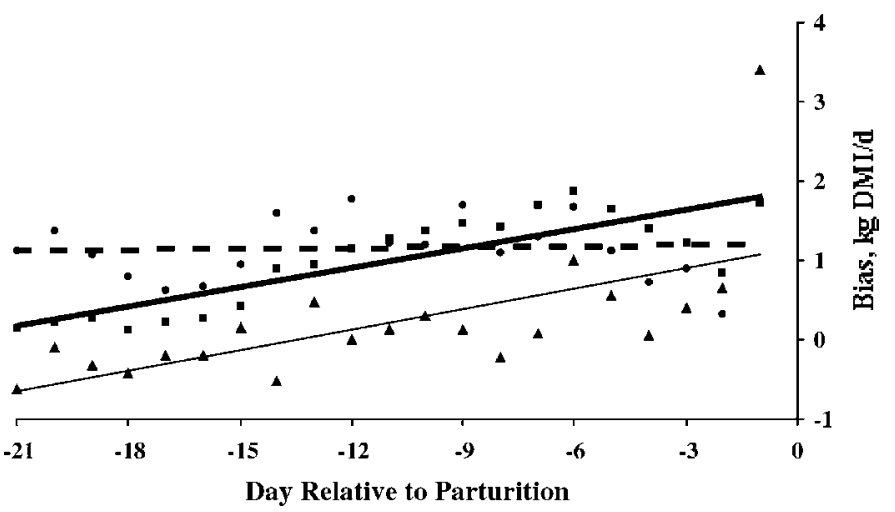

Figure 4. Changes in bias as heifers $\left(-, \mathbf{A} ; \mathrm{B}=0.09 \mathrm{t}+1.17, \mathrm{R}^{2}\right.$ $=0.42)$, cows $\left(\square ; \mathrm{B}=0.08 \mathrm{t}+1.88, \mathrm{R}^{2}=0.71\right)$, and obese cows $\left(---, ; B=0.003 t+1.20, R^{2}=0.002\right)$ from the validation database approached parturition. $\mathrm{B}=$ bias, $\mathrm{t}=$ day relative to parturition.

significantly over-predicted (mean bias $=1.13 \mathrm{~kg}$ DMI/ d; $P<0.0001$; Table 4). Moreover, precision $(24.9 \%)$ and accuracy $(22.3 \%)$ of the model for predicting DMI of cows were worse than for heifers. Precision and accuracy of the model for predicting DMI of OC were 19.5 and $30.3 \%$, respectively. Although this was an improvement compared to the model for predicting DMI of all cows, the difference between PDMI and ADMI was significantly different from zero (mean bias $=1.28 \mathrm{~kg} \mathrm{DMI} /$ $\mathrm{d}, P<0.03$; Table 4).

Time was the only independent variable in the exponential prediction models. Animal and dietary factors were not incorporated into the models. Failure to achieve better accuracy and precision might be due to differences between the ODB and VDB in characteristics of animals (Table 1), diets fed (Table 2), or other

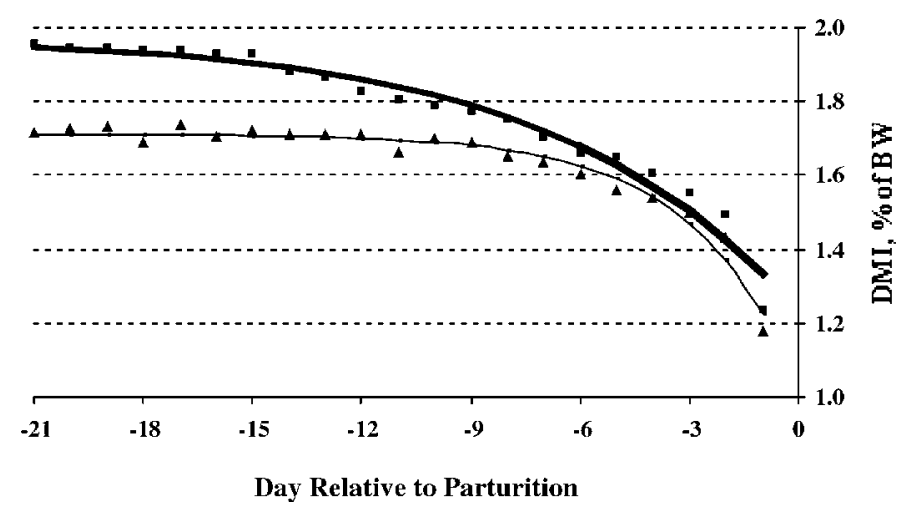

Figure 5. Daily means of actual and predicted DMI of heifers $(-, \mathbf{A})$ and cows $(-, \mathbf{D})$ from the combined database during the final $3 \mathrm{wk}$ of gestation. DMI is expressed as a percentage of BW recorded at $\mathrm{d} 21 \pm 0.8$. Average SD of actual DMI and average SE of predicted DM for heifers ( $\mathrm{n}=172)$ were 0.14 and 0.03 and for cows $(\mathrm{n}=527)$ were 0.19 and 0.04 , respectively. 
Table 4. Precision and accuracy of models for predicting DMI of prefresh transition Holsteins.

\begin{tabular}{|c|c|c|c|c|c|c|c|c|}
\hline \multirow[b]{2}{*}{ Parameter $^{2}$} & \multicolumn{3}{|c|}{ Descriptive statistics } & \multicolumn{5}{|c|}{ 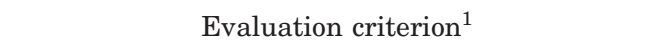 } \\
\hline & $\mathrm{n}$ & Mean & SD & $P>\mathrm{t}$ & $\begin{array}{l}\mathrm{MSPE} \\
(\mathrm{kg} / \mathrm{d})^{2}\end{array}$ & $\begin{array}{l}\mathrm{MPE} \\
(\mathrm{kg} / \mathrm{d})\end{array}$ & $\begin{array}{l}\mathrm{RPE} \\
(\%)\end{array}$ & $\begin{array}{l}\text { Accuracy } \\
(\%)\end{array}$ \\
\hline \multicolumn{9}{|l|}{ Heifer } \\
\hline Actual DMI, kg/d & 17 & 9.70 & 1.06 & $\ldots$ & . & $\ldots$ & . & $\ldots$ \\
\hline Predicted DMI, kg/d & 17 & 9.92 & 0.82 & & & & & . \\
\hline Bias, kg DMI/d & 17 & 0.22 & 0.81 & 0.28 & 0.81 & 0.90 & 9.25 & 65.0 \\
\hline \multicolumn{9}{|l|}{ Cow } \\
\hline Actual DMI, kg/d & 316 & 12.34 & 2.73 & . & . & . & . & \\
\hline Predicted DMI, kg/d & 316 & 13.47 & 2.73 & & & & & \\
\hline Bias, kg DMI/d & 316 & 1.13 & 2.78 & 0.0001 & 9.47 & 3.08 & 24.94 & 22.3 \\
\hline \multicolumn{9}{|l|}{ Cow with $\mathrm{BCS}>4.0$} \\
\hline Actual DMI, kg/d & 47 & 12.33 & 2.87 & $\ldots$ & & $\ldots$ & . & $\ldots$ \\
\hline Predicted DMI, kg/d & 47 & 13.61 & 1.27 & $\ldots$ & & $\ldots$ & $\ldots$ & $\ldots$ \\
\hline Bias, kg DMI/d & 47 & 1.28 & 2.77 & 0.03 & 5.76 & 2.40 & 19.5 & 30.3 \\
\hline
\end{tabular}

\footnotetext{
${ }^{1}$ Evaluation criterion: $\mathrm{MSPE}=$ mean square prediction error; $\mathrm{MPE}=$ mean prediction error; $\mathrm{RPE}=$ relative prediction error (precision); Accuracy = correlation between actual and predicted dry matter intakes $\left(\mathrm{r}_{\mathrm{ADMI}, \mathrm{PDMI}}\right)$.

${ }^{2}$ Parameter: bias $=$ predicted - actual.
}

factors. Table 5 shows the proportions of variance in DMI of animals contributed by day of gestation, BCS, and characteristics of diets fed to cows, particularly concentrations of NDF and EE, were different between the ODB and VDB. Rumen undegradable protein, RDP, $\mathrm{NDF}, \mathrm{EE}$, and day of gestation accounted for $0.3,0.4$, $19.9,22.3$, and $57.1 \%$ of the variation in DMI of OC in the ODB and $7.2,0.4,5.0,5.0$, and $82.3 \%$ in the VDB, respectively.

\section{Proposed Models}

The ODB and the VDB were combined to generate final models for predicting DMI. When combining heifers and cows, the model for DMI as a percentage of BW was $\operatorname{DMI}(\mathrm{t})=1.923-0.724 \mathrm{e}^{(0.174 \mathrm{t})}$. The $\mathrm{R}^{2}=0.97$ when fitting the model to daily means or 0.11 when fitting the model to data prior to reduction of data to daily means. Figure 5 illustrates daily means of ADMI and PDMI during the final $3 \mathrm{wk}$ of gestation for heifers and cows. The proposed models for predicting DMI as a percentage of BW were $\mathrm{DMI}(\mathrm{t})=1.713-0.688 \mathrm{e}^{(0.344 \mathrm{t})}$ for heifers $\left(\mathrm{R}^{2}=0.96\right.$ or 0.07$)$ and $\mathrm{DMI}(\mathrm{t})=1.979-$ $0.756 \mathrm{e}^{(0.154 t)}$ for cows $\left(\mathrm{R}^{2}=0.97\right.$ or 0.12 ) (Table 6). Dry matter intake of heifers and cows at beginning of the prefresh transition period and magnitude of changes in DMI as they approached parturition were different $(P<0.0001$, for both the coefficient "a" and "k"), but change in their DMI at time of parturition was not ( $P$ $<0.24$, for the coefficient "p"). According to these models, average PDMI during the final 3 wk of gestation was 1.63 and $1.77 \%$ of BW for heifers and cows, respectively.

In a previous study, we showed that parity, BCS, and dietary nutrient composition affected DMI during the prefresh transition period (Hayirli et al; 2002). In the present study, we developed models for predicting DMI

Table 5. Proportion of variation in DMI contributed by day of gestation (time), animal and dietary factors during the final 3 weeks of gestation. ${ }^{1}$

\begin{tabular}{|c|c|c|c|c|c|c|c|c|c|c|c|c|}
\hline \multirow[b]{3}{*}{ Factor } & \multicolumn{6}{|c|}{ Original database } & \multicolumn{6}{|c|}{ Validation database } \\
\hline & \multicolumn{2}{|c|}{ All animals } & \multicolumn{2}{|c|}{ Heifers } & \multicolumn{2}{|c|}{ Cows } & \multicolumn{2}{|c|}{ All animals } & \multicolumn{2}{|c|}{ Heifers } & \multicolumn{2}{|c|}{ Cows } \\
\hline & $\%$ & $P<\mathrm{F}$ & $\%$ & $P<\mathrm{F}$ & $\%$ & $P<\mathrm{F}$ & $\%$ & $P<\mathrm{F}$ & $\%$ & $P<\mathrm{F}$ & $\%$ & $P<\mathrm{F}$ \\
\hline Parity & 25.5 & 0.0001 & & & & & 0.5 & 0.36 & & & & \\
\hline $\mathrm{BCS}$ & 7.6 & 0.0001 & 9.3 & 0.03 & 6.7 & 0.005 & 3.8 & 0.009 & 0.1 & 0.93 & 4.0 & 0.01 \\
\hline RUP, \% & 3.9 & 0.006 & 5.3 & 0.09 & 0.2 & 0.60 & 2.4 & 0.04 & $\mathrm{NE}$ & $\mathrm{NE}$ & 2.5 & 0.04 \\
\hline RDP, \% & 0.6 & 0.29 & 5.4 & 0.09 & 0.6 & 0.42 & 1.3 & 0.13 & $\mathrm{NE}$ & $\mathrm{NE}$ & 1.3 & 0.14 \\
\hline $\mathrm{CP}, \%$ & 0.2 & 0.57 & 2.4 & 0.32 & 1.6 & 0.17 & 2.9 & 0.02 & $\mathrm{NE}$ & $\mathrm{NE}$ & 3.0 & 0.03 \\
\hline $\mathrm{NDF}, \%$ & 15.0 & 0.0001 & 18.2 & 0.002 & 24.1 & 0.0001 & 14.8 & 0.0001 & $\mathrm{NE}$ & $\mathrm{NE}$ & 15.2 & 0.0001 \\
\hline EE, \% & 13.0 & 0.0001 & 32.6 & 0.0001 & 19.1 & 0.0001 & 1.3 & 0.13 & $\mathrm{NE}$ & $\mathrm{NE}$ & 1.3 & 0.14 \\
\hline Time & 34.4 & 0.0001 & 29.1 & 0.0001 & 49.3 & 0.0001 & 75.9 & 0.0001 & 99.9 & 0.0001 & 75.7 & 0.0001 \\
\hline
\end{tabular}

${ }^{1}$ Factor: $\mathrm{BCS}=$ body condition score; $\mathrm{EE}=$ ether extract; time = day relative to calving. Dietary factors were on a DM basis. Contribution of CP to variation in DMI was calculated in a separate model in which $\mathrm{CP}$ replaced RUP and RDP. NE = non-estimable. 
Table 6. Proposed models for predicting DMI as a percentage of BW of prefresh transition Holsteins.

\begin{tabular}{|c|c|c|c|c|c|}
\hline \multirow[b]{3}{*}{ Coefficient $^{2}$} & \multicolumn{4}{|c|}{ Category of animals ${ }^{1}$} & \multirow[b]{3}{*}{$P>\mathrm{Z}^{3}$} \\
\hline & \multicolumn{2}{|c|}{ Heifers $(\mathrm{n}=172)$} & \multicolumn{2}{|c|}{ Cows $(n=527)$} & \\
\hline & Estimate & $95 \% \mathrm{CI}$ & Estimate & $95 \% \mathrm{CI}$ & \\
\hline a & $1.713(0.009)$ & $1.695-1.732$ & $1.979(0.026)$ & $1.923-2.034$ & 0.0001 \\
\hline$-p$ & $0.688(0.047)$ & $0.786-0.589$ & $0.756(0.034)$ & $0.827-0.684$ & 0.24 \\
\hline $\mathrm{k}$ & $0.344(0.035)$ & $0.272-0.416$ & $0.154(0.020)$ & $0.112-0.197$ & 0.0001 \\
\hline $\mathrm{R}^{2}$ & 0.96 & & 0.97 & & $\ldots$ \\
\hline \multicolumn{6}{|c|}{$\begin{array}{l}{ }^{1} \text { Numbers in the parentheses are SE of estimates. } \mathrm{CI}=\text { confidence interval. } \\
{ }^{2} \text { Coefficients of nonlinear equations }\left(\mathrm{DMI}(\mathrm{t})=\mathrm{a}+\mathrm{pe} \mathrm{e}^{(\mathrm{kt})}\right) \text { were obtained using the Gauss-Newton Method } \\
\text { after reducing data to daily means, where } \mathrm{DMI}(\mathrm{t})=\mathrm{DMI} \text { as a percentage of body weight }(\mathrm{BW}) \text { at time } \mathrm{t} \text {, a } \\
=\text { asymptotic intercept at time }-\infty, \mathrm{p}=\text { the change in intake }(\mathrm{kg}) \text { from the asymptotic intercept until parturition, } \\
\mathrm{k}=\text { rate constant influencing the shape of the curve, and } \mathrm{t}=\text { day relative to parturition expressed as days } \\
\text { pregnant }-280 \text {. DMI as a percentage of } \mathrm{BW} \text { at any given time was always expressed as a percentage of } \\
\text { BW recorded at } \mathrm{d} 21 \pm 0.8 . \mathrm{R}^{2}=[1-(\text { residual/corrected total })] \text {. }\end{array}$} \\
\hline \multicolumn{6}{|c|}{$\begin{array}{l}{ }^{3} \text { Probability of significance was obtained by pair-wise comparison of regression coefficients using Z-test } \\
\text { for contrasting heifers vs. cows. }\end{array}$} \\
\hline
\end{tabular}

of heifers and cows separately. Incorporation of animal factors (e.g., parity and BCS) and nutrient composition into prediction models was not plausible due to overparameterization. However, differences in characteristic of animals and diets challenged the validity of these prediction models, suggesting that it is essential to adapt prediction models when these factors change. Multiple regression analysis revealed that these factors influenced regression coefficients of the DMI prediction models (Table 7). Parity, BCS, and dietary nutrients, particularly dietary NDF and EE concentrations, affected all prediction coefficients when animals were not categorized according to parity. Neither BCS nor nutri- ent composition of diets affected coefficients of the model predicting DMI of heifers, whereas BCS and particularly dietary NDF and EE concentrations influenced coefficients of the model for predicting DMI of cows. These adjustment factors can be considered for adapting these prediction models when animal and dietary factors vary.

\section{CONCLUSIONS}

We obtained DMI data during the final 3 wk of gestation from Holsteins that varied in parity and BCS and were fed different diets at several universities. The de-

Table 7. Adjustment factors in coefficients of models for predicting DMI as a percentage of BW of prefresh transition Holsteins.

\begin{tabular}{|c|c|c|c|c|c|c|c|c|}
\hline \multirow[b]{2}{*}{ Coefficient $^{2}$} & \multicolumn{8}{|c|}{ Adjustment coefficients ${ }^{1}$} \\
\hline & Intercept & Parity & BCS & RUP, \% & $\mathrm{RDP}, \%$ & $\mathrm{NDF}, \%$ & $\mathrm{EE}, \%$ & $\mathrm{CP}, \%$ \\
\hline \multicolumn{9}{|l|}{ All Animals } \\
\hline a & $3.54^{*}$ & $0.10^{*}$ & $-0.17^{*}$ & -0.04 & -0.003 & $-0.02 *$ & -0.03 & -0.01 \\
\hline $\mathrm{p}$ & $-2.15^{*}$ & 0.01 & $-0.22^{*}$ & 0.15 & -0.01 & $0.03 *$ & $-0.13^{*}$ & 0.03 \\
\hline $\mathrm{k}$ & 0.13 & $-0.05^{*}$ & $0.07 *$ & -0.01 & 0.01 & 0.0001 & $0.03^{*}$ & 0.000 \\
\hline \multicolumn{9}{|l|}{ Heifers } \\
\hline a & $6.73^{*}$ & . & -0.26 & -0.16 & 0.04 & $-0.05^{*}$ & -0.48 & 0.02 \\
\hline $\mathrm{p}$ & -2.33 & . & -0.03 & 0.01 & -0.03 & 0.02 & 0.18 & -0.03 \\
\hline $\mathrm{k}$ & -0.59 & $\ldots$ & 0.04 & 0.01 & 0.04 & 0.006 & 0.06 & 0.03 \\
\hline \multicolumn{9}{|l|}{ Cows } \\
\hline $\mathrm{a}$ & $3.79 *$ & $\ldots$ & $-0.18^{*}$ & -0.02 & -0.02 & $-0.02^{*}$ & -0.02 & -0.02 \\
\hline $\mathrm{p}$ & $-2.22^{*}$ & $\ldots$ & $-0.26^{*}$ & 0.15 & 0.02 & $0.03 *$ & $-0.13^{*}$ & 0.05 \\
\hline $\mathrm{k}$ & 0.13 & $\ldots$ & $0.09 *$ & 0.005 & -0.02 & -0.0001 & 0.03 & -0.01 \\
\hline
\end{tabular}

${ }^{1}$ Nutrients were on a DM basis. Estimates of CP were calculated in a separate model in which CP replaced RUP and RDP. BCS = body condition score; EE = ether extract.

${ }^{2}$ Coefficients of nonlinear equations (DMI $\left.(\mathrm{t})=\mathrm{a}+\mathrm{pe}^{(\mathrm{kt})}\right)$ were obtained using the Gauss-Newton Method, where DMI $(\mathrm{t})=\mathrm{DMI}$ as a percentage of body weight $(\mathrm{BW})$ at time $\mathrm{t}$, a = asymptotic intercept at time $-\infty$, $\mathrm{p}=$ the change in intake (kg) from the asymptotic intercept until parturition, $\mathrm{k}=$ rate constant influencing the shape of the curve, and $t=$ day relative to parturition expressed as days pregnant -280 . DMI as a percentage of BW at any given time was always expressed as a percentage of BW recorded at $\mathrm{d} 21 \pm 0.8$. $* P<0.05$. 
crease in DMI during the prefresh transition period was fitted to an exponential function. The model generated from the ODB was more reliable for predicting ADMI of heifers than cows in the VDB. Failure was attributed to inconsistencies in characteristics of cows and nutrient compositions of diets fed to cows in the ODB and VDB. The exponential model was more successful at predicting DMI when using subsets of the ODB and VDB that contained cows with BCS $>4.0$ that were fed more consistent diets. Regression coefficients of the models can change depending upon BCS of animals and nutrient composition of diets fed. Although these models predict DMI, which can be useful for diet formulation for prefresh transition dairy cattle, they are still subject to further improvements.

\section{ACKNOWLEDGMENTS}

The authors would like to thank D. K. Beede, M. J. VandeHaar, L. H. Kilmer, J. K. Drackley, D. J. Carroll, L. A. Holden, G. A Varga, S. S. Donkin, R. J. Van Saun, and C. J. Sniffen for providing data sets used for this study.

\section{REFERENCES}

Allen, S. K., D. J. Carroll, and B. A. Barton. 1995. The effects of the sources of supplemental energy pre- and postpartum on lactation and reproductive performance of dairy cattle. J. Dairy Sci. 78 (Suppl. 1):164. (Abstr.).

Bell, A. W. 1995. Regulation of organic nutrient metabolism during transition from late pregnancy to early lactation. J Anim. Sci. 73:2804-2819.

Bertics, S. J., R. R. Grummer, C. Cadorniga-Valino, and E. E. Stoddard. 1992. Effect of prepartum dry matter intake on liver triglyceride concentration and early lactation. J. Dairy Sci. 75:19141922.

Berkey, D. 1994. Applied calculus. 3rd ed. Sounders Co., Orlando, FL.

Dann, H. M., G. A. Varga, and D. E. Putnam. 1999. Improving energy supply to late gestation and early postpartum dairy cows. J. Dairy Sci. 82:1765-1778.

Draper, N., and H. Smith. 1996. Applied Regression Analysis. 2nd ed. John Wiley \& Sons Co., New York, NY.

Duncan, J. S. 1998. Role of phosphoenolpyruvate carboxykinase in periparturient and ketotic dairy cows. M.S. Thesis. Oregon State University, Corvallis, OR.

Eastridge, M. L., H. F. Bucholtz, A. L. Slater, and C. S. Hall. 1998. Nutrient requirements for dairy cattle of the National Research Council versus some commonly used ration software. J. Dairy Sci. 81:3049-3062.

Edmonson, A. J., I. J. Lean, L. D. Weaver, T. Farver, and G. Webster. 1989. A body condition scoring chart for Holstein dairy cows. J. Dairy Sci. 46:243-251.

Greenfield, R. B., M. J. Cecava, T. R. Johnson, and S. S. Donkin. 2000. Impact of dietary protein amount and rumen undegradability on intake, peripartum liver triglyceride, plasma metabolites and milk production in transition dairy cattle. J. Dairy Sci. 83:703710.

Grum, D. E., J. K. Drackley, R. S. Younker, D. W. LaCount, and J. J. Veenhuizen. 1996. Nutrition during the dry period and hepatic lipid metabolism of periparturient dairy cows. J. Dairy Sci. 79:1850-1864.
Grummer, R. R. 1995. Impact of changes in organic nutrient metabolism on feeding the transition dairy cow. J. Anim. Sci. 73:2820-2833.

Grummer, R. R., P. C. Hoffman, M. L. Luck, and S. J. Bertics. 1995. Effect of prepartum and postpartum dietary energy on growth and lactation of primiparous cows. J. Dairy Sci. 78:172-180.

Hayirli, A. 1997. Effects of protein nutrition during the periparturient period on milk yield and health status of dairy cows. M.S. Thesis, Iowa State University, Ames, IA.

Hayirli, A., R. R. Grummer, E. V. Nordheim, and P. M. Crump. 2002. Animal and dietary factors affecting feed intake during the transition period in Holsteins. J. Dairy Sci. 85:3430-3443.

Kertz, A. F., L. F. Reutzel, and G. M. Thompson. 1991. Dry matter intake from parturition to midlactation. J. Dairy Sci. 74:22902298.

Marquardt, J. P., R. L. Horst, and N. A. Jorgensen. 1997. Effect of parity on dry matter intake at parturition in dairy cattle. J. Dairy Sci. 60:929-934.

Minor, D. J., S. L. Trower, B. D. Strang, R. D. Shaver, and R. R. Grummer. 1998. Effects of nonfiber carbohydrate and niacin on periparturient metabolic status and lactation of dairy cows. J. Dairy Sci. 81:189-200.

Moore, S. J., M. J. VandeHaar, B. K. Sharma, T. E. Pilbeam, D. K. Beede, H. F. Busholtz, J. S. Liesman, R. L. Horst, and J. P. Goff. 2000. Effects of altering dietary cation-anion difference on calcium and energy metabolism in peripartum cows. J. Dairy Sci. 83:2095-2104.

National Research Council. 1987. Predicting Feed Intake of FoodProducing Animals. National Academy Press, Washington, DC.

National Research Council. 1989. Nutritional Requirements of Dairy Cattle. 6th rev. ed. Natl. Acad. Sci., Washington, DC.

National Research Council. 2001. Nutritional Requirements of Dairy Cattle. 7th rev. ed. Natl. Acad. Sci., Washington, DC.

Neter, J., H. M. Kutner, J. C. Nachtsheim, and W. Wasserman. 1990. Applied Linear Statistical Models. 4th ed. Irwin Inc., Chicago, IL.

Nocek, J. E. 1995. Nutritional aspects of the transition cow. Pages 121-137 in Proc. Cornell Nutrition Conference for Feed Manufacturers. Ithaca, NY.

Overton, T. R., J. K. Drackley, G. N. Douglas, L. S. Emmert, and J. H. Clark. 1998. Hepatic gluconeogenesis and whole-body protein metabolism of periparturient dairy cows as affected by source of energy and intake of the prepartum diet. J. Dairy Sci. 81 (Suppl. 1):295. (Abstr.).

SAS User's Guide. Statistics, Version 7th ed. 1998. SAS Inst., Inc., Cary, NC.

Skaar, T. C., R. R. Grummer, M. R., Dentine, and R. H. Stauffacher. 1989. Seasonal effects of prepartum and postpartum fat and niacin feeding on lactation performance and lipid metabolism. J. Dairy Sci. 72:2028-2038.

Soder, K. J., and L. A. Holden. 1999. Dry matter intake and milk yield and composition of cows fed yeast prepartum and postpartum. J. Dairy Sci. 82:605-610.

Roseler, D. K., D. G. Fox, A. N. Pell, and L. E. Chase. 1997. Evaluation of alternative equations for prediction of intake for Holstein dairy cows. J. Dairy Sci. 80:864-877.

VandeHaar, M. J., G. Yousif, B. K. Sharma, T. H. Herdt, R. S. Emery, M. S. Allen, and J. S. Liesman. 1999. Effect of energy and protein density of prepartum diets on fat and protein metabolism of dairy cattle in the periparturient period. J. Dairy Sci. 82:1282-1295.

Van Saun, J. R. 1991. Dry cow nutrition: The key to improve fresh cow performance. The Veterinary Clinics of North America. 7:599-620.

Van Saun, J. R., S. C. Idleman, and C. J. Sniffen. 1993. Effect of undegradable protein amount fed prepartum on postpartum production in first lactation Holstein cows. J. Dairy Sci. 76:236-244.

Vazquez-Anon, M., S. J. Bertics, and R. R. Grummer. 1997. The effect of dietary energy source during mid to late lactation liver triglyceride and lactation performance of dairy cows. J. Dairy Sci. 80:2504-2512. 